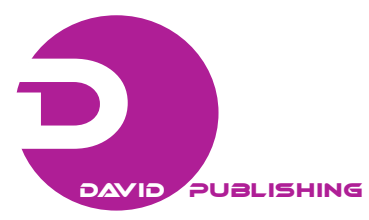

\title{
Framework for Quality Improvement of Infrastructure
}

\section{Projects}

\author{
Abukar Warsame \\ Department of Real Estate and Construction Management, School of Architecture and Built Environment, Royal Institute of \\ Technology (KTH), Stockholm 100 44, Sweden
}

\begin{abstract}
In order to achieve high quality that not only gives acceptable return value to society but also satisfies the needs of all the stakeholders of infrastructure projects, comprehensive understanding of issues pertaining to the quality of the project is needed. The aim of this study is to provide an overview the most common procurement methods used in constructing infrastructure transport projects and analyze how these methods contribute to the desired quality of the final product in relation to client competence. An on-line survey of construction actors was carried out to ascertain quality level of Swedish infrastructure transport projects and determinant factors of quality problems. An equal number of respondents indicated that the quality of infrastructure projects has either increased or remained same level over the past twenty years. Respondents also pointed out lack of client competence that is vital in realizing the desired quality level through proper procurement, monitoring and evaluation procedures. Public clients heavily rely on traditional design-build procurement that requires considerable client involvement of a project. Thus, the association of quality problems and lack of client competence may not be a mere coincidence but an overlooked outcome of current situation.
\end{abstract}

Key words: Competence, infrastructure transport, procurement, quality, warranties.

\section{Introduction}

Transport infrastructure transport projects are essential to economic activity and growth of a society. They are characterized as having long-life and long gestation processes as well as being capital intensive $[1,2]$. The sheer size of transport infrastructure projects often necessitates government involvement in terms of financing, developing, operating and maintaining them. Several arguments that explain government involvement in delivering infrastructure transport were outlined by Ref. [3]. One of the arguments is divergence of interest between public and private sector that makes transport infrastructure a product that cannot be easily delivered by the private sector.

However, government involvement in procuring infrastructure transport projects has been reduced for a

Corresponding author: Abukar Warsame, Ph.D., research fields: real estate economics and construction management. E-mail: abukar.warsame@abe.kth.se. lot of reasons while private sector participation has been on the rise lately $[1,4]$. Private sector involvement in developing major infrastructure transport projects such as roads and railways were often motivated by the financial constraints faced by the public sector [4]. The private sector may provide more efficiently and faster delivery of infrastructure transport than public sector because of higher management expertise and autonomy as well as lower levels of regulation and control that is associated with private sector [2]. Private sector efficiency allows government to share the associated risk of asset procurement and service delivery with the private sector [5]. Development of new products and technologies that lead to cost reduction and quality improvement also contributed to increased private sector participation [5] even though cost-cutting and desire of better quality are sometimes difficult to achieve both of them simultaneously [6].

Some of the causes of project success and failure can be traced back to the procurement method and 
how the owners selected that method $[7,8]$. The owners or clients are the most critical to project success [9] and their characteristics such as expertise and experience are the moderating factors on the performance procurement system chosen [10]. A UK government report [11] claims that "performance in the successful delivery of outcomes is strongly dependent on the skills of the client, not simply on the contract structure”.

The Swedish construction industry is facing a shortage of skilled workers and ageing of existing staff [12]. Since quality performance and the effectiveness of any selected procurement method partially hinges on the competence of client's workforce, it is crucial to examine how different procurement methods could be affected by the scarcity of client competence, experience and expertise. The aim of this paper is to examine the most dominant procurement methods used in constructing infrastructure transport projects and the role that client competence played on achieving the desired quality of the final product. Identifying some of factors that are associated with quality problems, i.e., lack of competence and at what stage of the construction process that these factors are critical will allow procurement officers and decision makers to contemplate which procurement method is appropriate to certain situations.

\section{Literature Review}

A survey conducted by the International Federation of Consulting Engineers [13] found that decreasing quality of construction is a worldwide phenomenon that is mainly caused by inappropriate mechanism of project delivery such as poor consultant and contractor selection, bad design, poor project supervision and inadequate material and workmanship. Other authors [3, 14, 15] identified several factors that have significant influence on the quality performance of a project however one common denominator of all these inadequacies or quality problems is the lack of client competence. Project manager's competence, top management support and interaction between project's participants are external contributors that enhance the project quality performance from its existing level while owner's competence is an internal contributor in the sense that owners tend to retain the quality performance at the existing level itself $[3,14]$.

A competent project manager and project team were highly ranked among the top five project success factors in a study carried out by Nguyen et al. [15]. Client incompetence often were blamed on flawed expectations and requirements placed on contractors [16]. Respondents in Ref. [16] survey pointed out incompetent client were unaware of the requirement they should or did in fact place on the supplier and thus contractors were inclined towards not to following these requirements. The FIDIC [13] finding also highlights the importance of client competence during the planning and design stage as well as during the tendering and construction stages. It emphasizes how the actors from the demand-side of the construction process such as client and engineer (consultant) could play a big role in improving the quality of construction.

During the operation and maintenance phase, assessment of the quality is challenging since the expected life of many infrastructure projects is quite long. Customer satisfaction surveys are sometimes used as a proxy for the quality level of a product. Though this approach can give an indication of quality level at certain point in time, it could be difficult to objectively assess the quality level of road infrastructure from end-users' point of view. A survey of Swedish Transportation Administration [17] exemplifies the difficult of ascertaining reliable measurement of satisfaction level from road users. The survey found that drivers were not only dissatisfied with road conditions but also private and professional drivers have different opinion about the level of dissatisfaction. Many road administrations from the countries that participated in this study 
reported shrinking staff due to retirement and to the attractiveness of private sector employment. This report also has noted that new types of contracts require broader project management skills and practical experience and thus there is need for key competences such as operations, road surfacing and specialist engineers [17]. Further discussion on the implication of client competence in relation to the quality of infrastructure projects will be covered later (Section 5). However, the most common procurement methods and how they defer in terms of quality aspect will be discussed next.

\section{Procurement Methods}

Procurement methods are often classified based on how construction activities such as design, construction, and operation and management are delegated among actors in the project. Different financing options of infrastructure projects also influence this classification. According to Ref. [18], procurement systems are classified as: traditional (separated), design and construct (integrated), management (packaged) and collaborative (relational). Short description of procurement methods, which is similar to Ref. [18] classification, will be described as follows.

\subsection{Traditional Procurement (Separated)}

Traditional procurement method of DBB (design-bid-build) with negotiated or separated competitive bidding fits this type of classification. DBB procurement method is prescriptive by nature where owners with in-house designers or with appointed consultant prepare the project design and tender documents. QC (quality control) and QA (quality assurance) activities are either carried out altogether by the contractor or sometimes the client is responsible for quality assurance while contractor is responsible for quality control process. In Sweden, twenty-five years ago, the client (Swedish Transportation Administration) has transferred quality control and quality assurance to the contractors and accepts only the final project if it meets the expected quality level of performance.

Mandell and Nilsson [19] studied some 1,400 road construction and renewal projects procured by the Swedish road administration between 2000 and 2009. The large majority of these projects were procured in the form of unit price contracts or DBB. Pietroforte and Miller [20] noted that DBB was the most dominant form of infrastructure procurement after the Second World War in the US although during the last decade DB (design and build) has grown steadily in both private and public sector. Unit price contracts dominate procurement of projects in the transport sector in Sweden [19] and in US [21]. One shortcoming of DBB approach is that it does not take into account the increasing operation and maintenance costs of the ageing infrastructure [20]. Furthermore, DBB procurement focuses the price of the project rather than quality.

\subsection{Management (Packaged)}

$\mathrm{CM}$ (construction management), management contracting, and design and mange belong to this category. Basically, an owner enters agreement with a construction firm that carries out leadership, administration and management of specified services [22]. According to Ref. [22], CM is seldom used in road construction because of the relatively small number of contractors involve in road construction that is easily manageable by clients.

\subsection{Design and Build Procurement (Integrated)}

In order to address certain problems associated with DBB and improve the performance of construction projects, integrated DB (design-build) procurement and its variants such as $\mathrm{DBO} / \mathrm{M}$ (design-build-operate/maintenance) have been promoted to be an appropriate alternative procurement strategy. DB is an integrated procurement system where the client contracts with a single contracting 
organization to carry out both design and construction responsibilities with or without inclusion of operation and maintenance contracts. One common feature of these types of contracts is that client is responsible for entirely and directly financing the project [20]. DB would allow contractors to tender the most economical design that meets the requirements of the client and use materials and innovation techniques that produces desirable outcome for the client. However, DB procurement method demands different skills and competences than the traditional procurement (DBB) that public servants are accustomed [22]. A distinct criterion for DB contracts is the RFPs (requests for proposals) along the price and technical proposals. The RFPs contains owners' objectives and needs with respect to quality and the design/builders are required to interpret those requirements and submit their proposals [23].

There is no definite agreement on whether the overall quality achieved under DB procurement is better than DBB. Client's expectation of design quality does not differ between DB and DBB though contractors under DB tend to choose only the necessary design that leads to savings [24]. One major problem found by Ref. [23] is that owners of public projects who have used DB procurement often executed with DBB mentality because majority of RFPs contained a DBB construction quality control plan requirement. As Ref. [25] argue, the use of DB procurement does not mean that an inexperienced client can simply leave all the project and responsibility to the DB contractor. Design-build procurement is much easier for a client with sufficient design and past construction experience [25].

\subsection{Public-Private-Partnerships and Its Variants (Relational)}

A further categorization of procurement methods is based on how financing of the project is formulated. This category is an extension of integrated design-build variations except that the private sector is now financially involved in the provision of a project. Design-build-finance-operate or BOT, as it is known outside the US [20], BOOT (build-own-operate-transfer), and BOO (build-own-operate) belong to this group. These procurement methods have longer contract period than the typical integrated procurement methods financed by the publicly sector. However, there is no clear-cut definition between PPPs (public-private-partnerships) and BOOT except that one can observe an increase in the number of stakeholders of PPP projects [26]. DBFO (design-build-finance-operate) or BOT (build-operate-transfer) is another example of PPPs arrangement.

Though the use of PPPs for procurement of public infrastructure projects is not something new to most of the developed and developing countries, comprehensive performance assessment of the projects undertaken with PPPs has been difficult due to the divergence between the duration of PPPs contracts and the longevity of infrastructure projects. Infrastructure projects could last decades or centuries while PPPs contracts are often in the range of 30 years. Thus, it is difficult to have a full assessment of infrastructure projects that are constructed under PPPs arrangements. Procurement of infrastructure projects with PPP involves many parties with conflicting objectives and thus requires extensive client competence and expertise [5]. Private operator may heavily invest in cost reduction technologies without taking into consideration their impact on the quality of the project [6]. Realized quality could be better or worse under private contracting depending on the impact of any cost reduction technologies employed by the private actors [6]. PPP arrangements to surface transport infrastructure are complex with many pitfalls and thus require strong client competence and expertise [27]. Public sector experience with the design and build procurement provides adequate knowledge and capacity that is needed to handle complex PPPs arrangements [27]. Based on 
international experiences, Swedish Transport Administration report [28] accentuates the importance of highly competent client organization for efficient and successful PPP projects. According to Ref. [28], the only infrastructure project that has been built with PPPs arrangements so far is Arlanda railway link (Arlandabanan).

\section{Research Method}

After a pilot survey with a number of practitioners and academics in the field of construction, an on-line questionnaire containing 29 questions was sent to 128 selected respondents (45 contractors, 35 clients, 37 consultants and 11 regional traffic offices). The composition of respondents was intended to ensure a fair representation of different stakeholders of construction projects that would allow us to ascertain the extent of quality concerns in the sector. Through the author's research reference group and organization websites as well as professional association's websites, the appropriate persons in each organization that could answer the questionnaire were identified. After few questions related to the information of respondents, respondents were asked their general assessment of the quality problems today and the past. In order to establish the prevalence of quality problems in relation to different phases (construction phase, final inspection phase and during warrant period), respondents were asked their opinion about how often quality deficiency occurs and who discovers as well as what actions are taken when quality problems are discovered.

Warrant contracting is usually used with performance-based specifications and is intended to replace stringent quality control and inspection regimes associated with traditional procurement [29]. When quality deficiency is discovered three possible actions can be taken by project managers: complete removal of the defective product or structure, repair without complete removal, and deductions from payments if the quality is not exactly the required level but acceptable within certain limits. A set of questions that was intended to give people a sense of understanding on whether warranty contracting has improved quality of construction projects after the client transferred quality assurance responsibility to the contractor were also included in the questionnaire.

The rest of the questions of the survey (15 questions) were statements that are intended to ascertain important attributes such as competence of construction actors, project characteristics etc. that may have contributed quality problems or lack of quality improvement. Respondents were also asked to comment on each question and statement in order to solicit their candid view about the quality of infrastructure projects.

\section{Frame Work for Quality Improvement}

\subsection{Construction Quality}

Brockmann [30] argues that construction projects such as buildings or infrastructure are typically quasi-credence goods meaning that their qualities are ex-ante intangible but ex-post tangible. His argument is based on the classification of three types of quality [31], search qualities which are known before purchase, experience qualities which are known costlessly only after purchase, and credence qualities which are expensive to assess even after purchase. Construction goods do not exhibit search qualities since the quality of construction goods can not be determined at the time of signing contract [30]. However, once the contract is carried out and the project is completed ex-post search qualities could become tangible. Similarly, construction goods also differ from experience goods since experience qualities are based on a high frequency of contracting between the same client and contractor [30]. The nature of construction business and government regulations as well as competition rules does not foster repetitive interaction among actors in construction sector. On the contrary, Vassallo [32] argues that quality of most of infrastructure projects 
are observable after their use and classified them as "experience goods". He claims that infrastructure quality is verifiable though the cost of measuring quality is not usually low.

It could be argued that since different procurement methods provide construction clients an opportunity to influence design and construction qualities, a client's internal capacity and available resources such as design and inspection teams as well as his competence and skills play a major role determining whether the desired product has the characteristics of search, experience or credence qualities. If a client or his representative has the capability to carry out all the necessary quality control and quality assurance activities, this will ensure that the quality of the project becomes not only observable but verifiable during the construction until the operation phase starts or even during the warrant period. When client and contractor have also long term relationship high frequency contracting, which is a necessary condition for experience qualities [30], could be materialized.

The quality and long term performance of the infrastructure is subject to many external and stochastic factors such as the level of usage of infrastructure, efficiency of intended operation, weather, and frequency of planned and unplanned maintenance. Thus, the quality of realization during operation and maintenance is may be what makes construction goods to be treated as quasi-credence goods.

\subsection{Client Competence}

A client organization with highly skilled and sufficiently experienced workforce is most likely capable to ascertain many project risk factors than client organization with less endowed human capital resources. There are distinctive competencies that are highly required when client is employing a specific procurement method. The traditional procurement (design-bid-build) where client has multiple contracts with different actors for the provision of infrastructure projects is a good starting point to identify most relevant responsibilities of client. Client is expected to have enough manpower resources with appropriate skills and expertise in different areas such as financial, technical and contracting management. Some of the notable client competences are: ability to define project scope and objectives, establish design criteria and performance requirement, carry out preliminary survey and geotechnical investigations, ensure constructability of design, perform control and inspection of quality performance, and prepare possible mitigation actions and procedures when performance objectives are not met.

Competences that are needed for risk sharing activities where the client uses a procurement strategy such as design-build and performance-based contracts with warranties are much similar to the above list except that client is oblige to prepare RFPs for DB contracts instead of complete design of the project. Previous experience with DB related projects were found to be among the key competences that DB clients in China should possess [25]. Competences that are needed for risk transferring activities where client engages procurement strategies such as DBFO with or without maintenance and other forms of PPPs are now more related to management, financial, legal and commercial activities.

A resourceful client organization could use these extraordinary technical competencies and expertise to transform experience qualities to search qualities or even credence qualities to experience qualities. This transition between types of qualities would have certain implication on how client selects appropriate procurement methods. Thus, the above representation could improve understanding the impact of different procurement methods on client's workforces and their skill development.

\section{Results and Discussion}

\subsection{Quality Concerns}

Sixty seven respondents that translate to a $52 \%$ response rate completed the survey. According to the 
respondents, quality of construction projects constructed in last five years is either at the same level or even better than the quality level of projects built twenty years ago. Same numbers of respondent (43\%) believe that quality level is higher today or has not changed during this period.

Responses from client side were almost inconclusive when asked who finds out quality problems during construction (client or contractor). A possible explanation for this inconclusiveness could be that the client has little opportunity to discover quality problems during this phase since quality assurance responsibilities were transferred to the contractor. Respondents indicate that clients' complain is limited to few isolated projects (47\%) though $21 \%$ of them pointed out that client complain about quality problems is present in majority of the projects. With regard to quality problems discovered during the final inspection, $44 \%$ of the respondents say that few isolated projects encountered quality problems while $26 \%$ of them indicated that majority of the projects experienced quality problems.

A combined 43 respondents (66\%) indicated that quality problems discovered during the final inspection get fixed by means of reparations without complete removal or contractors accepted payment deductions. The situation is somewhat different when it comes to quality problems during warranty period or shortly after it expires. Majority of respondents (42) indicate that clients very seldom discover or complain about quality during this period. If quality deficiencies are discovered during the warrant period, a complete removal or payment deductions are not the preferred options. Twenty-five respondents or $42 \%$ of them say that very seldom contractors remove the defected part or structure. Another 20\% (20 respondents) say that payment deductions do happen very seldom. The prevailing measure to rectify quality problem during warranty period is reparation without complete removal. These responses give an indication on how project managers and client representatives react when they discover quality problems but the underlying fact is that these kinds of decisions require higher competence and experience that is in short supply in the client organization's workforce as the following responses suggest.

\subsection{Client Competence Concerns}

Responses from the questions related to competence of client with regard to quality problems of infrastructure projects were very strongly negative. Respondents indicated that client's lack of competence is major factor of quality problems of infrastructure projects. Approximately $80 \%$ of respondents partially or totally agree with the statement that the quality problem in the finished structure is highly dependent on the client's competence. Similarly, $72 \%$ of them indicated that tendering documents contributed quality problems of final product. Respondents also pointed out (80\%) that designers of the project play a major role on the quality problems experienced in the finished project.

The above finding provides an opportunity to investigate the role of client competence on different procurement methods and how much skills, expertise and competence of client workforces and client experience is demanded by each type of procurement method.

A prognosis from Ref. [12] points out that one third of the construction industry's workforce will retire between 2005 and 2015. The study also shows that the construction industry has a higher proportion of older people and a smaller proportion of younger employees compared to the total employment. In Finland, employees' retirement and reduction of client staff are reported to be behind diminishing client experience and competence [22]. The implication of human capital scarcity is that public clients face an uphill battle in attracting new talented and competent graduates as well as retaining them in a competitive market. Some of the respondents in the survey also raised this issue of ageing client workforce, 
non-replacement policy of retired staff and their concern of new skilled workers not joining the public transport sector.

\subsection{Procurement Method Concerns: Client Competence and Quality}

According to Ref. [33], no one procurement method is likely to be better than others for any project although one procurement method could be more appropriate or suitable than others for an individual project. In Sweden, traditional procurement (design-bid-build) or unit price contract has been the most dominant contract form used for the delivery of transport infrastructure projects [19, 28]. The question is whether this heavy reliance of DBB method in the Swedish infrastructure transport is supported by undisputed higher performance achievement compared to other procurement methods or the Swedish Road and Railway administration has chosen it for other reasons.

Several possible explanations have been offered as to why a clients or owners keep using repeatedly the same procurement method especially the dominance of the traditional procurement method. Familiarity of DBB within the industry and its ability to satisfy public accountability, client control over the project's outcome and cost certainty makes easy and attractive method for public sector to rely on more often than other procurement methods [24, 33]. Avoidance of uncertainty is another explanation. Lædre et al [8] claim that owners select a well-known procurement route since unknown procurement method could introduce new uncertainty. When owners attain experiences from the use of certain procurement procedure and management routines, it will encourage them to keep using this combination in their next project [8]. DBB procurement are generally considered to be suitable when client wants to settle upon a design before construction commitments, take advantage of existing designs or the client has the only experience necessary for this kind of project [22].
Public owners are not motivated to be creative when selecting the procurement route because creative thinking is seldom rewarded while project failure will be criticized [8]. Thus, it is convenient to use the same procurement system. One important question that could be raised about the heave reliance of public sector on DBB procurement method is "can the benefits and confidence that a continuous use of DBB offers to the public sector be sustainable for a long period of time?

While cost effectiveness, strong client control of the project and flexibility are some of the benefits associated with DBB, one can not overlook the downside of the use of DBB procurement for several reasons: First, if the client's lack of competence (as the survey indicates) is due to a shortage of skilled and experience workforce then the use of DBB could exacerbate the situation since $\mathrm{DBB}$ requires higher client involvement; Secondly, the use of DBB contracts has been seen as one of the factors that contributed to the lower productivity and lagging performance of the Swedish construction industry [19, 34]; thus, a lack of client competence and its negative impact on quality of infrastructure projects will worsen the situation and inflict further distress to the sagging industry's productivity.

The frequent use of DBB procurement raises other concerns on top of its susceptibility for human capital shortages. In US, economic factors and change of procurement laws will cause an increase of public client's use of other procurement methods such as DB, DBO and BOT [20]. Similarly, since April 2000 UK government requires projects should be procured by PFI (public-financing-initiative), prime contracting or design-build [8]. In Sweden, limited projects have so far been procured with other procurement method than traditional DBB method. However, the use of performance-based contracts such as DB (with short-term warranties) and DBOM (with long-term warranties) is painted as good move toward public sector readiness to embrace PPPs arrangements [28]. 
The use of warranty contracting has given some leeway for the public sector to deal with quality problems that could arise from contractors not complying with the specifications and the design [29, 35]. Warranties has offered an alternative way to assure performance when State highway agencies faced staff and budget shortage and still needed to increase the quality and life-cycle performance of pavement [35]. Warranties guarantee that contractors are responsible to repair and replace defects both during the construction and warranty period [29]. One of the main features of warranties is that quality is measured based on actual product performance over time rather than construction materials and workmanship [36]. In other words, contractor has the incentive to use any construction methods and products as long as they meet client's specified quality performance. The finding of the survey seems to support that contractors with warranty obligations have actually succeeded to produce the desired quality performance of infrastructure projects. More than seventy percent of respondents have indicated that only few or no infrastructure projects encountered quality problems during the warranty period or after the warranty expired (after 1 to 3 years).

\section{Conclusions}

The success and failure of infrastructure project to achieve their performance objectives in terms of end-users' needs and societies' economic benefits are determined by number of factors including the procurement strategy. The choice of an appropriate method to procure a specific infrastructure project depends on many factors and client competence is one of the most important of them. The client is not only the owner of the project and the initiator of the concept but also represents the end-user and thus responsible for determining their needs objectively, interpreting them accurately and selecting design and construction teams that can deliver successfully the desired product. All these activities and responsibilities require a very strong client competence with skills, expertise and experiences necessary to carry out their technical, financial and management duties.

As the findings of the survey and other previous studies mentioned in this paper indicate, lack of client competence is one of the factors that contribute quality problems of infrastructure projects. Traditional procurement method, which is the most common method used by the STA (Swedish Transportation Administration), demands the highest client involvement in the project compare to other procurement methods. In light of shortage of skilled and experienced workforce in the public sector and the heavy reliance of the sector on this traditional procurement, it is plausible to assume that the association of quality problems and lack of client competence is not a mere coincidence but an overlooked outcome of current situation.

Many benefits that are associated with traditional procurement method such as client's control of the project, design flexibility and familiarity of the sector with this method and public sector's achievement of quality standards through warranties can not be disregarded. However, the need to have enough public sector staff with good skills and competencies is very crucial to improve the quality of infrastructure transport projects. Strong and broader client competence would enable the public agency staff to properly identify the needs of the customers that are necessary inputs to determine the performance requirement and the objectives of the project. Increased client competence would ensure that many unknown quality attributes are transformed to known elements and known-unknowns will be shared or transferred accordingly: On one hand, product with quality attributes similar to manufacture goods (search goods) could benefit a procurement method that relies more on standardization and the use of more prefabricated products; on the other hand, product with experience and credence qualities would benefit 
more on the use of procurement methods that foster frequent and long-term relationships such as performance-based contracts and PPPs arrangements. Furthermore, other procurement methods such as relational (PPPs), integrated (DB) and performance-based contracts (DBOM) require strong client competence, skills and expertise that match those possessed by the commercial and business-oriented private sector.

\section{References}

[1] D. Grimsey, M. Lewis, Evaluating the risks of public private partnerships for infrastructure projects, International Journal of Public Management 20 (2) (2002) 107-118.

[2] A. Ng, M. Loosemore, Risk allocation in the private provision of public infrastructure, International Journal of Project Management 25 (4) (2006) 66-76.

[3] S. Rienstra, P. Nijkamp, Lessons from priavete financing of transport infrastructure: Dutch infrastructure in the 19th century and European projects in the 20th century, Revue Économique 48 (2) (1997) 231-245.

[4] G. Hodge, C. Greve, Public-private partnerships: An international performance review, Public Administration Review 67 (3) (2007) 545-558.

[5] E. Cheung, A. Chang, Suitability of procuring large public works by PPP in Hong Kong, Engineering, Construction and Architectural Management 17 (3) (2010) 292-308.

[6] A. Estache, A. Iimi, C. Ruzzier, Procurement in Infrastructure: What Does Theory Tell Us?, World Bank Policy Research Working Paper Series, 2009.

[7] J. Tookey, M. Murray, C. Hardcastle, D. Langford, Construction procurement routes: Re-defining the contours of construction procurement, Engineering, Construction and Architectural Management 8 (1) (2001) 20-30.

[8] O. Lædre, K. Austeng, O.J. Klakegg, Procurement routes in public building and construction projects, Journal of Construction Engineering and Management 132 (7) (2006) 689-696.

[9] K. Molenaar, A. Songer, Model for public sector design-build project selection, Journal of Construction Engineering and Management 124 (6) (1988) 467-479.

[10] D.T. Luu, S.T. Ng, S.E. Chen, Parameters governing the selection of procurement system-An empirical survey, Engineering, Construction and Architectural Management 10 (3) (2003) 209-218.

[11] H.M. Treasury, Infrastructure Procurement: Delivering
Long-Term Value, 2008, http://www.hmtreasury.gov.uk /d/bud08_procurement_533.pdf (accessed Nov. 10, 2010).

[12] Competence in the Civil Engineering Sector, Final report, FIA (Renewal in the Civil Engineering Industry), 2005. (in Swedish)

[13] Improving the Quality of Construction, FIDIC-International Federation of Consulting Engineers, 2004.

[14] K. Jha, K. Iyer, Critical factors affecting quality performance in construction projects, Total Quality Management 17 (9) (2006) 1155-1170.

[15] L.D. Nguyen, S. Ogunlana, D.T. Xuan, A study on project success factors in large construction projects in Vietnam, Engineering, Construction and Architectural Management 11 (6) (2004) 404-413.

[16] A. Landin, ISO 9001 within the Swedish construction sector, Construction Management and Economics 15 (5) (2000) 509-518.

[17] STA (Swedish Transportation Administration), The Road to Excellence-An International Benchmarking between National Road Admistrations, 2010, http:// publikationswebbutik.vv.se/upload/5591/2010_075_the_r oad_to_excellence_.pdf (accessed Oct. 11, 2010).

[18] P. Love, P. Davis, D. Edwards, D. Baccarini, Uncertainty avoidance: Public sector clients and procurement selection, International Journal of Public Sector Management 21 (7) (2008) 753-776.

[19] S. Mandell, J.E. Nilsson, A Comparison of nit price and fixed price contracts for infrastructure construction projects, Working Papers, Swedish National Road \& Transport Research Institute (VTI), 2010.

[20] R. Pietroforte, J. Miller, Procurement methods for US infrastructure: Historical perspectives and recent trends, Building Research \& Information 30 (6) (2002) 425-434.

[21] D. Gransberg, C. del Puerto, D. Humphrey, Relating cost growth from the initial estimate to design fee for transportation projects, Journal of Construction Engineering and Management 133 (6) (2007) 404-408.

[22] T. Koppinnen, P. Lanhdenperä, The Current and Future Performance of Road Project Delivery Methods, VTT, Finland, 2004, http://www.vtt.fi/inf/pdf/publications /2004/P549.pdf (accessed Nov. 15, 2010).

[23] D. Gransberg, K. Molenaar, Analysis of Owner's Design and Construction Quality Management Approaches in Design/Build Projects, Journal of Management in Engineering 20 (4) (2004) 162-169.

[24] T. Koppinnen, P. Lanhdenperä, Road sector experience on project delivery methods, VTT, Finland, 2004, http://www.vtt.fi/inf/pdf/tiedotteet/2004/T2260.pdf (accessed Nov. 15, 2010).

[25] B. Xia, A. Chan, Key competences of design-build clients 
in China, Journal of Facilities Management 8 (2) (2010) 114-129.

[26] M. Jefferies, W.D. McGeorge, Using public-private partnerships (PPPs) to procure social infrastructure in Australia, Engineering, Construction and Architectural Management 16 (5) (2009) 415-437.

[27] Transport Infrastructure Investment: Options for Effeciency, OECD (Organization for Economic Co-operation and Development) report, International Transport Forum, Transportation Research Center, 2008.

[28] A Swedish Model for PPP in Infrastructure Investment, STA (Swedish Transportation Administration), 2008, http://epppc.hu/documents/cikkek945aswedishmodelforp ppininfrastructureinvestment.pdf (accessed Sep. 15, 2010).

[29] Q. Cui, M.E. Bayraktar, M. Hastak, I. Minkarah, Use of warranties on highway projects: A real option perspective, Journal of Management in Engineering 20 (3) (2004) 118-125.

[30] C. Brockmann, Global constrution markets and contractors, in: L. Ruddock (Ed.), Economics for the Modern Built Environment, Taylor and Francis, London,
2009.

[31] M. Darby, E. Karni, Free competition and the optimal amount of fruad, Journal of Law and Economics 16 (1) (1973) 67-88.

[32] J. Vassallo, Implementation of quality criteria in tendering and regulating infrastructure management contracts, Journal of Construction Engineering and Management 133 (8) (2007) 553-561.

[33] P. Love, R. Skitmore, G. Earl, Selecting an appropriate procurement method for a building project, Construction Management and Economics 16 (2) (1998) 221-233.

[34] J.E. Nilsson, The value of puplic-private-partnerships in infrastructure, Working Papers, Swedish National Road \& Transport Research Institute (VTI), 2009.

[35] FHWA (Federal Highway Agency) Highway quality compendium: FHWA-IF-07-012, 2007, http:// www.fhwa.dot.gov/construction/pubs/hif07012/07012.pd f (accessed Sep. 15, 2010).

[36] k. Guo, E. Minchin, T. Ferragut, The shift to warranties and performance specifications: What of method specifications?, Construction Management and Economics 23 (9) (2005) 953-963. 